\title{
Ideologi Surat Kabar dalam Pemberitaan Terorisme
}

\author{
Fajar Syuderajat \\ Fakultas Ilmu Komunikasi \\ Universitas Padjadjaran Bandung \\ fajarsyuderajat@gmail.com
}

\begin{abstract}
This paper this study was to determine the ideology of Newspaper Coverage Off Execution Amrozy Cs. on Newspaper Kompas and Republika. The method used in this research is the analysis method semiotics model of Ferdinand de Saussure with a qualitative approach. The results showed that: (a) Option speech text, as well as the news angle images of photographs or illustrations that reproduce the graph becomes a news event is strongly influenced by the ideology of the media is concerned. (B) Compass showing partiality to the international agenda by using the term "terrorists" in its message. This is also strengthened by the news in the form of photo illustrations which only includes figures or portraits of security officers. (C) Republike has a distinctive news angle in reporting the death penalty convicted Bali Bombing Case. They appear at the peculiarities of the text selection, angle coverage, as well as news illustrations are photographs which contains many figures or portraits Amrozi.
\end{abstract}

Keywords: Ideology, Newspapers, Semiotics

\section{ABSTRAK}

Tulisan ini penelitian untuk mengetahui Ideologi Surat Kabar dalam Pemberitaan Eksekusi Mati Amrozy Cs. Pada Surat Kabar Kompas dan Republika. Metode yang digunakan dalam penelitian ini ialah metode analisis semiotika model Ferdinand De Saussure dengan pendekatan kualitatif. Hasil penelitian menunjukkan bahwa: (a) Pilihan teks ujaran, angle pemberitaan serta ilustrasi gambar berupa foto atau grafik yang mereproduksi peristiwa menjadi sebuah berita sangat dipengaruhi oleh ideologi media yang bersangkutan. (b) Kompas memperlihatkan keberpihakan kepada agenda internasional dengan menggunakan term "teroris" dalam pemberitaannya. Hal ini juga diperkuat dengan ilustrasi pemberitaan berupa foto yang hanya memuat figur atau potret petugas keamanan. (c) Republika memiliki angle pemberitaan yang khas dalam memberitakan hukuman mati terpidana Kasus Bom Bali. Kekhasan tersebut muncul pada pilihan teks, angle pemberitaan, serta ilustrasi berita berupa foto yang banyak memuat figur atau potret Amrozi dkk.

Kata Kunci : Ideologi, Surat Kabar, Semiotika 
Fajar Syuderajat

\section{Pendahuluan}

Media masa selalu berhubungan dengan ideologi dan hegemoni. Hal ini berkaitan dengan cara bagaimana sebuah realitas wacana atau teks ditafsirkan dan dimaknakan dengan cara pandang tertentu. Wacana atau teks untuk konsumsi publik tidak seharusnya dilihat dalam keadaan mentah tapi hal tersebut merupakan sesuatu yang diorganisasi ulang dan dikontekstualisasikan agar sejalan dengan bentuk ekspresi tertentu yang sedang atau ingin digunakan. Bentuk ekspresi teks yang diorganisasi ulang dan dikontekstualisasikan tersebut memiliki dampak besar terhadap para pembacanya. Maka dari itu dibutuhkan pemaknaan yang bersifat intertekstual bagi para pembaca.

Pemaknaan dan makna tidak an sich ada dalam teks atau wacana itu sendiri (John Fiske, 1988:143-144). Hal ini bisa dijelaskan bahwa ketika kita membaca teks, maka makna tidak akan kita temukan dalam teks yang bersangkutan. Yang kita temukan adalah pesan dalam sebuah teks. Sebuah peristiwa yang direkam oleh media massa baru mendapat makna ketika peristiwa tersebut ditempatkan dalam identifikasi kultural dimana berita tersebut hadir. Peristiwa demi peristiwa diatur dan dikelola sedemikian rupa oleh para awak media, dalam hal ini oleh para wartawan. Itu berarti bahwa para awak media menempatkan peristiwa ke dalam peta makna. Identifikasi sosial, kategorisasi, dan kontekstualisasi dari peristiwa adalah proses penting di mana peristiwa itu dibuat bermakna bagi khalayak.

Berbicara mengenai peristiwa yang bermakna, tanggal 12 Oktober 2002, dua buah bom meledak di Bali. Bom pertama meledak di Paddys Café, termasuk berdaya ledak rendah (low explosive), dan disusul kemudian dengan ledakan bom berkekuatan sangat tinggi (bigh explosive) di Sari Club, Kuta. Saat itu pemerintah Bush tengah gencar-gencarnya merekrut negara-negara lain, salah satunya Indonesia, agar mau bergabung dengan AS dalam perang melawan terorisme.

Ketika itu Presiden Megawati kurang memberikan tanggapan. Atas desakan umat Islam, pemerintah Megawati kala itu gamang merespon ajakan Bush. Dan meledaklah Bom Bali. Usai tragedi itu, pemerintah Megawati pun mau tidak mau berperan serta, aktif dalam perang melawan apa yang dinamakan AS sebagai terorisme. Indonesia saat itu sangat pro-aktif menangkapi para aktivis Islam, hingga banyak kalangan secara sinis menyebut republik ini telah menjadi negara bagian AS ke-51.

Amrozi dan kawan-kawan telah mengakui membom Paddys Café, yang berdaya ledak rendah. Namun mereka menolak sebagai pelaku yang meledakan 
bom berkekuatan sangat tinggi yang meledak di Sari Club, Kuta. "Kami tidak memiliki kemampuan untuk membuat bom sedahsyat itu, " ujar Imam Samudera suatu ketika.

Mantan Kepala Badan Intelijen Negara (BIN) alm. Letjen. ZA. Maulani saat itu berkeyakinan bahwa yang meledak di Sari Club adalah bom mikro nuklir. "Hanya mikro nuklir yang memiliki efek ledakan seperti itu, bukan RDX apalagi TNT. Dan mikro nuklir yang ada di dunia ini hanya diproduksi di instalasi nuklir Dimona, milik Israel.”

Temuan Maulani dikuatkan oleh Joe Vialls. Mantan pakar demolisi dari kesatuan elit tentara Inggris SAS, yang kemudian desersi dan menetap di Australia sebagai pengamat masalah-masalah intelijen juga meyakini bom yang meledak di Sari Club adalah mikro nuklir, karena ada efek cendawannya. "Efek cendawan merupakan satu-satunya efek yang bisa dibuat oleh bom nuklir. Dan bom yang meledak di Sari Club, Kuta-Bali, memang mikro nuklir, " ujar Vialls.

Letjen Maulani menghembuskan nafas beberapa waktu kemudian karena sakit. Dan Joe Vialls juga menemui ajal beberapa tahun kemudian. Kematiannya mencurigakan karena sangat mendadak. Ada indikasi Vialls diracun oleh MOSSAD, sama seperti Litvinenko diracun oleh agen-agen KGB atas perintah Vladimir Putin.

Singkatnya, Amrozy dan kawan-kawan kemudian menemukan akhir hidupnya di depan regu tembak pada Hari Minggu dini hari, Tanggal 9 November 2008 (911-08). Hampir semua media massa nasional merepresentasikan peristiwa itu menjadi beadline. Tentu saja dengan ujaran teks yang berbeda pada setiap medianya.

Dalam konteks ini, menarik apabila menyimak pendapat Daniel Hallin mengenai peta ideologi dalam seluruh konstelasi pemahaman suatu teks. Dia berpendapat bahwa dunia jurnalis dibagi dalam tiga bidang ideologi, yaitu bidang penyimpangan, bidang kontroversi dan bidang konsensus. Bidangbidang dalam pemetaan ideologis ini akan mempengaruhi bagaimana para awak media dan media massa membingkai dan menyeleksi suatu peristiwa untuk dijadikan berita media. Pembaca dan pembuat makna yang mencoba untuk memaknakan suatu teks tertentu terjalin dalam lingkaran relasi dengan sistem nilai yang lebih besar. Sistem nilai yang lebih besar itu adalah ideologi.

Berdasarkan uraian latar belakang tersebut, penulis membuat suatu rumusan masalah yaitu, bagaimana "Ideologi Surat Kabar Kompas dan Republika yang Tercermin dalam Pemberitaan Eksekusi Mati Amrozy Cs." Adapun tujuan penelitian ini adalah untuk mengetahui dan menjabarkan 
Ideologi Surat Kabar Kompas dan Republika dalam Pemberitaan Eksekusi Mati Amrozy Cs.

Kajian ilmu komunikasi menjadi sangat menarik ketika komunikasi pada tingkat praksisnya menyentuh aspek kemanusiaan. Tentu saja, aspek kemanusiaan tersebut meliputi aspek sosial, ekonomi, politik, ideologi, psikologi dan kebudayaan manusia itu sendiri (Littlejohn, 2002). Dalam perkembangan kebudayaan manusia, komunikasi massa menjadi proses komunikasi yang mempunyai tingkat pengaruh yang cukup signifikan pada kehidupan sehari-hari.

Berita, dalam konteks komunikasi massa yang berkembang sampai sekarang, selalu muncul dalam benak dan pikiran manusia. Berita yang disusun dalam benak manusia bukan merupakan peristiwa manusia. Berita bukan adalah peristiwa itu sendiri. Berita merupakan usaha rekonstruksi kerangka peristiwa yang terjadi. Maka, berita dalam konteks komunikasi massa, lebih merupakan inti yang disesuaikan dengan kerangka acuan yang dipertimbangkan agar peristiwa itu memiliki makna bagi para pembacanya.

Berita dalam kapasitasnya sebagai pembentuk dan dinamisator pengolahan interpretasi atas peristiwa manusia, menjadi hal yang sangat penting dalam proses pembentukan konstruk sosial. Berita, pada titik tertentu, sangat mempengaruhi manusia merumuskan pandangannya tentang dunia (Weltanschaung). Pandangan terhadap dunia adalah bingkai yang dibuat oleh manusia untuk menggambarkan tentang apa dan bagaimana dunia dipahami. Berbagai pengalaman hidup manusia dimaknai dalam bingkai tersebut. Tanpa adanya bingkai yang jelas, kejadian, peristiwa dan pengalaman manusia akan terlihat "kacau" dan chaos. Bingkai pengalaman dapat dilihat sebagai "skenario awal" yang memposisikan setiap pengalaman dan peristiwa dalam plot cerita yang kurang lebih runtut, rasional dan sistematis.

Usaha untuk memahami proses relasional antara ideologi, media massa dan ekonomi politik media termasuk dalam kategori perspektif ekonomi politik. Vincent Mosco menyebutkan bahwa:

"...Ekonomi politik komunikasi berupaya menjadikan media bukan sebagai pusat perhatian, dengan konsentrasi lebih diarahkan pada kajian mengenai keterkaitannya dengan ekonomi, politik dan faktor-faktor lainnya. Menjadikan media bukan sebagai pusat 
perhatian berarti memandang sistem komunikasi sebagai terintegrasi dengan proses ekonomi, politik, sosial, dan budaya fundamental dalam masyarakat."

Dalam kajian media, perspektif ekonomi politik media merupakan bagian dari perspektif kritis selain cultural studies, teori kritis, feminisme, teori resepsi pesan, dan semiotika (Mohammadi \& Mohammadi, 1990, hal. 15).

Pendekatan ekonomi politik merupakan sebuah kajian yang diidentifikasi sebagai kelompok pendekatan kritis (McQuail, 2000:82). Pendekatan ekonomi politik memfokuskan pada kajian utama tentang hubungan antara struktur ekonomi-politik, dinamika media, dan ideologi media itu sendiri.

Penelitian tentang ideologi media ini, mengambil sampel surat kabar Kompas dan Republika atas dasar bahwa kedua media massa nasional tersebut memiliki tiras tertinggi di Indonesia diantara media cetak lainnya selain itu juga distribusi yang masif hingga mencapai tingkat kabupaten di daerah pelosok Indonesia.

\section{Ilustrasi Hitam Putih Versus Berwarna Penuh}

Setiap teks pemberitaan pada media cetak akan dikuatkan oleh ilustrasi berupa gambar atau foto yang relevan dengan topik berita yang disajikan. Selain bertujuan merepresentasikan peristiwa, hal ini secara latent akan menguatkan ujaran pada teks yang berkaitan dengan ideologi dan ekonomi politik media bersangkutan.

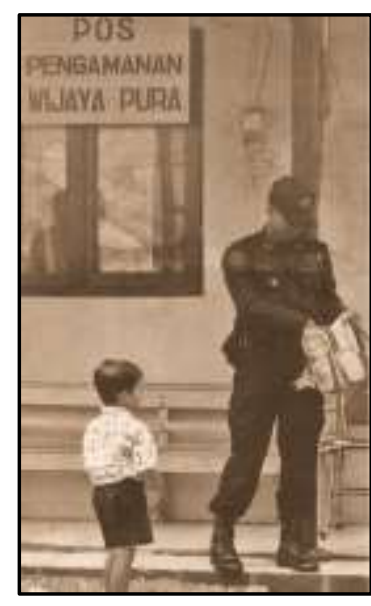

Gambar 1



Gambar 2 
Fajar Syuderajat

Foto Berita Republika (9/11/2008) Foto Berita Kompas (7/11/2008)

Kedua foto di atas merupakan salah satu dari ilustrasi pemberitaan seputar hukuman mati (versi Kompas) atau eksekusi mati (versi Republika). Foto-foto yang berkonteks dengan pemberitaan tersebut memiliki nuansa yang mirip antara Kompas pada satu sisi dan Republika di sisi lainnya. Pada sisi Kompas, foto-foto dibuat dalam warna hitam putih sedangkan Republika memuat foto-foto dengan warna penuh.

Secara sensorik persepsional, gambar yang berwarna penuh akan lebih mendekati keadaan objek aslinya, karenanya hal ini lebih dapat menyentuh sisi emosional para pembaca dibandingkan dengan hanya foto yang hitam putih. Foto dengan warna penuh juga akan menimbulkan sensasi yang aktual dibanding dengan foto hitam putih yang berkesan lawas.

Selain itu secara ekonomi, biaya produksi foto berwarna penuh pada surat kabar jauh lebih mahal atau dua kali lipat dibanding dengan yang hitam putih. Hal ini disebabkan penggunaan tinta warna penuh CYMK (cyan, yellow, magenta, black) lebih banyak serta membutuhkan plat cetak yang lebih rumit dibandingkan dengan foto hitam putih. Untuk ruang atau besar foto yang sama dan di halaman yang sama ongkos cetak foto berwarna penuh dapat $60 \%$ lebih mahal dibandingkan dengan ongkos cetak foto hitam putih.

\section{Potret Petugas Versus Potret Amrozy Dkk.}

Setiap penulisan berita atau reproduksi peristiwa kedalam teks membutuhkan angle atau sudut pandang. Sudut pandang ini lah yang membuat sebuah tulisan dengan topik sama akan menjadi berbeda bahkan juga sangat mungkin bertolak belakang. Sudut pandang pada akhirnya secara sadar atau tidak sadar merupakan keberpihakan terhadap ideologi tertentu; dalam konteks ini, ideologi yang dianut dapat oleh sang wartawan atau media yang diwakilinya. 


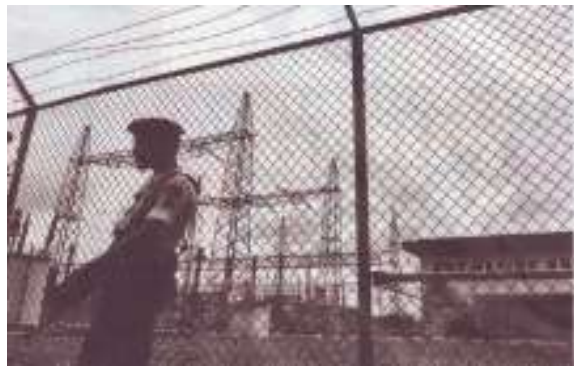

Gambar 3

Foto Berita Kompas, Senin 3 November 2008

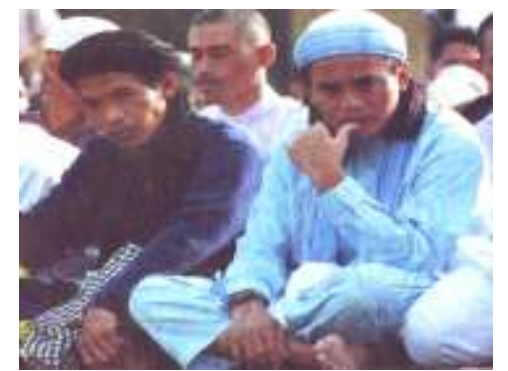

Gambar 4

Foto Berita Republika

Minggu 9 November 2008

Dalam memilih ilustrasi berita juga sangat terkait dengan sudut pandang. Kata "memilih" memiliki arti mengambil satu atau beberapa dan menampikkan yang lainnya. Artinya proses seleksi ilustrasi yang dianggap layak cetak bukan hanya persoalan teknis dan artistik foto saja namun juga berkaitan dengan ideologi media.

Pilihan siapa yang dimunculkan adalah refleksi dari policy atau ideologi media. Kontras foto petugas dengan foto Amrozi dan kawan kawan secara implisit menyiratkan titik berdiri perspektif pemberitaan. Kemarahan dan pemahfuman (konsekuensi dari perbuatan) atau simpati yang hendak disampaikan secara implisit. Paling tidak titik berdiri pemberitaan Kompas dilihat dari ilustrasi yang dimunculkan adalah titik berdiri "petugas keamanan" sedangkan pemberitaan Republika memiliki titik berdiri Amrozi dan kawan kawan.

\section{Foto Ambulans Versus Foto Keranda}

Pada segmen penutup rangkaian berita mengenai Amrozi dan kawankawan Senin 10 November 2008, Kompas berjudul "Hukuman Mati: Amrozi Cs Telah Dimakamkan." Dengan ilustrasi berita yaitu foto ambulans di tengah kerumunan massa dan yang terlihat dalam frame foto adalah kerumunan massa yang didominasi oleh petugas keamanan dan para wartawan. Teks "Hukuman mati" pada judul dicetak dengan warna merah (dapat lihat pada lampiran) dan sudut pengambilan foto diambil sejajar dengan objek (medium angle) dengan bingkai medium shot juga.

Sedangkan Republika pada hari yang sama, meluncurkan berita penutup berjudul: "Atasi Radikalisme," dengan ilustrasi foto keranda yang diangkat di tengah kerumunan massa yang didominasi oleh warga 
dan kerabat. Foto diambil dengan sudut pandang dari atas (bigh angle) dengan bingkai longshot.

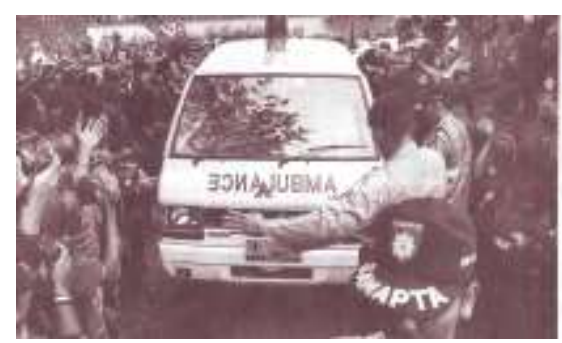

Gambar 5

Foto Berita Kompas

Senin 10 November 2008



Gambar 6

Foto Berita Republika

Senin 10 November 2008

Berdasarkan penanda-penanda yang dimuat oleh Kompas dapat ditafsirkan: (a) ambulans adalah kendaraan penyelamat walaupun juga sebagai angkutan orang mati. Penyelamat dalam konteks membawa orang sakit atau terluka dan segera dibawa ke rumah sakit; kemudian sebagai angkutan orang mati, ambulans akan dibawa ke rumah sakit, ke rumah duka dan atau hendak dimakamkan. (b) ambulans di tengah kerumunan massa yang didominasi oleh petugas keamanan dan para wartawan dapat menyiratkan sebuah peristiwa kecelakaan atau kriminal yang memakan korban. (c) Teks "Hukuman mati" pada judul dicetak dengan warna merah menyiratkan adanya penegasan atau penguatan. Dapat juga memiliki makna peringatan atau larangan. (d) sudut pengambilan foto yang diambil sejajar dengan objek (medium angle) dengan bingkai medium shot juga, memiliki kesan yang kurang emosional dan terasa sempit.

Sedangkan penanda-penanda yang dimuat oleh Republika dapat ditafsirkan: (a) foto keranda, sebagai sebuah simbol angkutan jenazah yang merujuk pada prosesi kematian dalam agama Islam setidaknya di Indonesia. (b) keranda yang diangkat di tengah kerumunan massa setidaknya menandakan orang yang ada di dalam keranda sangat dikenal dan banyak orang yang memiliki kepenasaran terhadapnya. (c) foto yang diambil dengan sudut pandang dari atas (high angle) dengan bingkai longshot akan memberikan dampak emosional yang kuat terlebih bingkai longshot akan mengesankan keluasan serta mampu memuat sebuah peristiwa secara utuh. 
Dari judul-judul di atas yang dimuat oleh Kompas maupun Republika ada beberapa teks yang menarik jika dikontraskan. Untuk merepresentasikan akibat perbuatan Amrozi dan kawan-kawan Kompas menggunakan teks: "Hukuman Mati" sedangkan Republika "Eksekusi Mati." Selanjutnya, untuk merepresentasikan bentuk tindakan yang dilakukan oleh Amrozi dan kawan-kawan Kompas menggunakan teks: "Terorisme" sedangkan Republika "Radikalisme."

Tabel 1 Judul Berita

\begin{tabular}{|c|c|}
\hline Judul Berita Kompas & Judul Berita Republika \\
\hline \multicolumn{2}{|c|}{ Terorisme: "Keluarga Amrozi dan Imam "Keluarga Amrozi akan } \\
\hline Samudra akan PK.” (03/11) & Ajukan PK.”(03/11) \\
\hline "Terorisme dan Individualisasi Perang." & "Amrozi Cs Telah \\
\hline$(06 / 11)$ & Dieksekusi.” (09/11) \\
\hline “Nusakambangan Disterilkan dari Truk & "Kronologi Eksekusi mati \\
\hline Proyek hingga Senin.”(07/11) & Amrozi dkk." (09/11) \\
\hline Terorisme: "Dua Helikopter Dikirim ke & “Amrozi dkk tak Sampaikan \\
\hline Nusakambangan.”(09/11) & Pesan Terakhir.” (09/11) \\
\hline Hukuman mati:"Amrozi Cs Telah & "Atasi Radikalisme." (10/11) \\
\hline Dimakamkan.” (10/11) & \\
\hline
\end{tabular}

Kemudian mengenai titik berdiri media terhadap objek berita dapat dikontraskan Judul berita hari yang sama yaitu Minggu (09/11/2008): Kompas menulis judul, "Terorisme: Dua Helikopter Dikirim ke Nusakambangan." Sedangkan Republika menulis judul, "Amrozi dkk tak Sampaikan Pesan Terakhir." Reproduksi peristiwa yang direpresentasikan melalui pemilihan teks tertentu secara implisit merupakan refleksi dari ideologi media yang bersangkutan.

\section{Hukuman Mati Versus Eksekusi Mati}

Hukuman: "siksa dsb. Yang dikenakan kepada orang yang melanggar undang-undang dsb; keputusan yang dijatubkan oleb hakim."

Hukuman Mati: "bukuman yang dijalankan dengan membunub (mis. menembak, menggantung) orang yang bersalah." 
Fajar Syuderajat

Eksekusi: "(1) pelaksanaan putusan bakim atau badan peradilan;

khususnya bukuman mati. (2) penyitaan dan penjualan harta orang yang berbutang."

Eksekusi Mati: "putusan hakim atau peradilan untuk bukuman mati."

Merujuk pada makna denotatif dari Kamus Besar Bahasa Indonesia dapat diinterpretasikan bahwa kata "hukuman" merupakan sesuatu yang wajar diterima atas tindakan yang dianggap atau diputuskan salah bagi penerima hukuman tersebut. Sedangkan kata "eksekusi" memiliki makna yang lebih luas walaupun juga berkaitan dengan putusan badan peradilan. Kata "eksekusi" digunakan juga didunia periklanan untuk melakukan menggantikan istilah produksi iklan.

\section{Terorisme Versus Radikalisme}

Terorisme:"penggunaan kekerasan untuk. menimbulkan ketakutan dalam usaha mencapai tujuan (terutama tujuan politik); praktik-praktik tindakan teror.”

Radikalisme:"(1) paham atau aliran yang radikal dalam politik; (2) paham atau aliran yang menginginkan perubahan atau pembaharuan sosial dan politik dengan cara keras atau drastis; (3) sikap ekstrem dalam suatu aliran politik."

Selain makna denotatif yang melekat, makna konotatif pada kata "terorisme" lahir dari labeling dunia barat terhadap aksi bunuh diri yang merengut nyawa orang lain secara massal. Ketimpangan atau standard ganda terjadi manakala aksi pembunuhan massal tidak diikuti dengan aksi bunuh diri sang pelaku. Dan kita sama-sama tahu bahwa kata "terorisme" sangat identik dengan aksi-aksi bunuh diri yang mengatasnamakan agama Islam.

Sedangkan makna kata "radikalisme" cenderung lebih netral karena dapat menjadi label bagi aksi-aksi yang tidak hanya berlandaskan religi tertentu namun juga terjadi pada wilayah aksi ideologi politik ekonomi. Bahkan berlandaskan pada makna etimologi, kata "radikalisme" berasal dari bahasa latin yaitu: radic yang memiliki arti "akar". Sehingga makna kata "radical" dapat juga dimaknakan "mengakar" atau "mendasar". Dengan demikian "radikalisme" adalah aliran (isme/ideologi) yang mengakar atau mendasar serta pengejawantahannya juga mengakar atau 
mendasar. Kurang lebih, kata "radikalisme" dapat disepadankan dengan kata "fundamentalisme".

\section{Judul Kompas Versus Judul Republika}

Judul pertama berasal dari Kompas-'Terorisme: Dua Helikopter Dikirim ke Nusakambangan"-menyiratkan titik berdiri tertentu media terhadap objek berita. Kompas seakan memposisikan diri sebagai pewarta yang menjauhkan diri dari realitas personal Amrozi dkk. dan memilih merepresentasikan kesibukan aktivitas para aparatur negara yang terkait dengan hukuman mati (versi Kompas)/eksekusi mati (versi Republika) terpidana kasus Bom Bali. Hal ini diperkuat dengan ilustrasi pemberitaan yang samasekali tidak menampilkan figur atau potret Amrozi dkk. Sebaliknya Kompas menampilkan figur atau potret petugaspetugas keamanan dalam berbagai aktivitasnya yang terkait.

Sedangkan, judul kedua dari Republika-"Amrozi dke tak Sampaikan Pesan Terakbir"-menyiratkan titik berdiri Republika yang seakan memilih posisi sebagai pewarta yang justru sangat mendekatkan diri terhadap objek beritanya. Frase "pesan terakhir" memiliki makna psikologis yang cukup mendalam, bahkan dapat diidentikan dengan surat wasiat bagi orang yang meninggal dunia. Titik berdiri yang seakan mendekatkan diri terhadap realitas personal Amrozi dkk. juga diperkuat dengan pilihan ilustrasi berita yang memunculkan sejumlah figur atau potret Amrozi dkk.

\section{PENUTUP}

Berdasarkan hasil penelitian tentang pemberitaan hukuman mati (versi Kompas) / eksekusi mati (versi Republika) terpidana Kasus Bom Bali maka dapat ditarik beberapa kesimpulan sebagai berikut: 1) Pilihan teks ujaran, angle pemberitaan serta ilustrasi gambar berupa foto atau grafik yang mereproduksi peristiwa menjadi sebuah berita sangat dipengaruhi oleh ideologi media yang bersangkutan, 2) Kompas yang secara anekdot disebut "komando pastur", secara implisit memperlihatkan keberpihakan kepada agenda internasional dengan menggunakan term "teroris" dalam pemberitaannya. Hal ini juga diperkuat dengan ilustrasi pemberitaan berupa foto yang berusaha 
Fajar Syuderajat

menjaga jarak terhadap realitas personal Amrozi dkk dengan hanya memuat figur atau potret petugas keamanan dalam hal ini polisi dengan berbagai aktivitasnya yang terkait dan 3) Republika sebagai surat kabar nasional Indonesia yang dalam proses berdirinya tak lepas dari ideologi Islam moderat memiliki angle pemberitaan yang khas dalam memberitakan hukuman mati (versi Kompas) / eksekusi mati (versi Republika) terpidana Kasus Bom Bali. Kekhasan tersebut muncul pada pilihan teks, angle pemberitaan, serta ilustrasi berita berupa foto yang banyak memuat figur atau potret Amrozi dkk.

\section{DAFTAR PUSTAKA}

Bignell, Jonathan. 2001. Media Semiotics, An Introduction. Manchaster University Press: London.

Curran, James and Richard Collins, 1986. Media, Culture and Society: A Critical Reader. Sage Publication: London.

Fairclough, Norman. 1998. Critical Discourse Analysis: The Critical Study of Language. Longman: London.

Fairclough, Norman. 1995. Media Discourse. Edward Arnold: New York.

Fiske, John. 1982. Introduction of Communication Studies. Routledge: London.

Hall, Stuart. 1992. Culture, Media dan Language. Routledge: London.

Littlejohn, Stephen. 2002. Theories of Human Communication. Wadsworth Publishing Company: California.

Mills, Sara. 1991. Discourse. Routledge: London.

Mosco, Vincent. 1996. The Political Economy of Communication. Sage Publication: New York.

Reese, Stephen D,. 2001. Framing Public Life. Lawrence Earlbaum Publisher: New Jersey.

Riggins, Stephen H,. 1997. The Language and Politics of Exclusion: Others in Discourse. Sage Publication: London.

Saverin, Werner. 1997. Communication Theories: Origins, Methods and Uses in the Mass Media. Longman: New York.

Shoemaker, Pamela cs (eds). 1991. Mediating The Message: Theories of Influences on Mass Media Content. Longman Group: London. 